\title{
Can You Only Diagnose What You Know? The Relation Between Teachers' Self-Regulation of Learning Concepts and Their Assessment of Students' Self-Regulation
}

\author{
Charlotte Dignath* and Lara Sprenger \\ DIPF, Leibniz Institute for Research and Information in Education, Frankfurt, Germany
}

Self-regulation of learning (SRL) positively affects achievement and motivation. Therefore, teachers are supposed to foster students' SRL by providing them with strategies. However, two preconditions have to be met: teachers need to diagnose their students' SRL to take instructional decisions about promoting SRL. To this end, teachers need knowledge about SRL to know what to diagnose. Only little research has investigated teachers' knowledge about SRL and its assessment yet. Thus, the

OPEN ACCESS

Edited by: Tova Michalsky,

Bar-llan University, Israel

Reviewed by:

Adar Ben-Eliyahu, University of Haifa, Israel Pamela Murphy, Ashford University, United States

*Correspondence: Charlotte Dignath dignath@dipf.de

Specialty section: This article was submitted to

Teacher Education,

a section of the journal

Frontiers in Education

Received: 21 July 2020 Accepted: 14 October 2020 Published: 12 November 2020

Citation:

Dignath C and Sprenger L (2020) Can You Only Diagnose What You

Know? The Relation Between

Teachers' Self-Regulation of Learning Concepts and Their Assessment of Students' Self-Regulation. Front. Educ. 5:585683. doi: 10.3389/feduc.2020.585683 aim of this study was to identify teachers' conceptions about SRL, to investigate their ideas about how to diagnose their students' SRL, and to test relationships between both. To this end, we developed two systematic coding schemes to analyze the conceptions about $\mathrm{SRL}$ and the ideas about assessing $\mathrm{SRL}$ in the classroom among a sample of 205 teachers. The coding schemes for teachers' open answers were developed based on models about SRL and were extended by deriving codes from the empirical data and produced satisfactory interrater reliability (conceptions about SRL: $\kappa=0.85$, SE $=0.03$; ideas about assessing SRL: $\kappa=0.63$, SE $=0.05$ ). The results showed that many teachers did not refer to any regulation procedure at all and described SRL mainly as student autonomy and self-directedness. Only few teachers had a comprehensive conception of the entire SRL cycle. We identified three patterns of teachers' conceptualizations of SRL: a motivation-oriented, an autonomy-oriented, and a regulation-oriented conceptualization of SRL. Regarding teachers' ideas about assessing their students' SRL, teachers mainly focused on cues that are not diagnostic of SRL. Yet, many teachers knew about portfolios to register SRL among students. Finally, our results suggest that, partly, teachers' ideas about assessing SRL varied as a function of their SRL concept: teachers with an autonomy-oriented conceptualization of SRL were more likely to use cues that are not diagnostic of SRL, such as unsystematic observation or off-task behavior. The results provide insights into teachers' conceptions of SRL and of its assessment. Implications for future research in the field of SRL will be drawn, in particular about how to support teachers in diagnosing and fostering SR among their students.

Keywords: self-regulation, learning strategies, teacher knowledge, teacher assessment, teacher learning 


\section{INTRODUCTION}

Self-regulating one's learning has proven to be an important skill for lifelong learning (Hattie and Yates, 2013; Organisation for Economic Co-operation and Development [OECD], 2014) that children should learn from early on in order to develop a functional and effective learning behavior rather than developing their own, inefficient, strategies by trial and error that tend to be difficult to change later on (e.g., Alexander et al., 1995). Whereas, historically, self-regulation of learning (SRL) ${ }^{1}$ has been regarded as a competence suitable for older learners (e.g., Veenman et al., 2006), recent educational developments, such as the implementation of digital learning environments, in particular due to school closures in the scope of the SARSCoV-2 pandemic, have noticeably shown how important it is that even young learners are able to self-regulate their learning. However, many novice and expert learners lack the necessary skills to self-regulate their learning (Leutwyler and Maag Merki, 2009). Research of the last decades has illustrated that SRL can already be found in very young learners (e.g., Whitebread and Neale, 2020) and that even primary school children can already benefit from strategy training to foster SRL (e.g., Dignath et al., 2008). Thus, promoting SRL should be a major goal for today's primary and secondary education. Yet, educators need to have a clear conceptualization of SRL in order to promote self-regulatory strategies in their classroom (Boekaerts, 1999). Moreover, based on this conceptualization, they need to assess how self-regulated each individual student is and which students need which type of support in order to foster SRL adaptively (Dignath and Veenman, 2020).

Imagine a foreign language teacher who aims to teach her students how to communicate about a certain topic in the foreign language. In order to do so, the teacher needs content knowledge about the foreign language (e.g., vocabulary and grammar), as well as pedagogical content knowledge about how to teach the foreign language. Thus, this teacher needs to have a correct conceptualization of the foreign language and needs to know how to use the vocabulary correctly within a sentence in order to teach her students successfully. In the same way, a teacher who aims to foster SRL needs to know what self-regulation entails and how to apply self-regulation strategies effectively. The foreign language teachers need to know about ways to assess the communication skills of her students in the foreign language. She may have a repertoire of diagnostic strategies that she applies to identify which student still needs support and which student is ready to advance to the next level. Based on these diagnostics, she can provide her students with assignments that suit the students' language skills. Comparably, a teacher who aims to foster SRL is required to find ways to identify the self-regulatory skills of her students in order to adaptively support her students' development of SRL.

To date, we have only little understanding yet about teachers' conceptualization of SRL and about their ideas about assessing their students' self-regulation. The few studies conducted in this

${ }^{1}$ With the term self-regulation of learning, we refer to a learner's regulation, thus, as the term self-regulated learning. field suggest that teachers' conceptualization of SRL does not necessarily reflect the components identified as important in SRL research (Callan and Shim, 2019). Moreover, most educators hold only limited knowledge about how to assess students' SRL (Michalsky, 2017). Yet, no research has been conducted yet about how teachers' conceptualization of SRL is associated with their ideas about assessing SRL. Thus, in order to enlarge our understanding about teachers' conceptualization and ideas regarding SRL and its assessment, the aim of this study was to investigate how educators conceptualize SRL compared to a scientific conceptualization of SRL, as well as to identify teachers' ideas about how to assess students' self-regulation skills.

\section{A Scientific Concept of Promoting Self-Regulation of Learning Conceptualizing Self-Regulation of Learning From a Scientific Perspective}

Self-regulated learners can set themselves task-specific goals that serve as a standard against which they evaluate their performance (Zimmerman, 2000). When self-regulated learners consider the result as having not met this standard, they respond to this internal feedback by adapting their approach to solve the academic task. The outcome of this self-evaluation influences the next learning phase, often involving a change in the initial strategies or even in the goal itself (Pintrich, 2000). Considering these three phases of the self-regulated learning cycle, most models of SRL draw on a forethought phase that includes goal setting and choice of strategies, a monitoring phase that comprises monitoring one's performance, and a reflection phase that serves to evaluate one's learning and that turns into a feedback loop that affects the upcoming forethought phase of the next learning cycle (see Zimmerman, 2000 for the most cited cyclical model of SRL; see Panadero, 2017 for a review of models on SRL).

When self-regulating one's learning, learners can regulate their cognition, their motivation and emotions, their behavior, and the context (Pintrich, 2004). Likewise, within the selfregulation process, several types of strategies can be detected that a learner applies during learning (e.g., Boekaerts, 1999): First, cognitive strategies, such as elaboration and organization of the learning content, serve the information processing related to task execution and are the key cognitive processes that self-regulation acts upon in order to attain the goal. Such strategies are specific to the subject and the learning content (see, e.g., Weinstein and Mayer, 1986 for a taxonomy of cognitive learning strategies). Second, the self-oriented feedback loop that characterizes self-regulation processes is executed through metacognitive monitoring and control processes. Research has shown that metacognitive strategies play the most important role in sustaining the self-regulation process (Corno, 2008). Metacognition is based on the idea that learners possess a control entity that builds on the ability to introspect and serves to monitor, reflect, evaluate, and control. Metacognition involves metacognitive knowledge that consists of knowledge of strategy, task, and person variables (Flavell, 1979), metacognitive experience that affects the learner's self-concept and the causal attributions (Efklides, 2011), and metacognitive strategies that 
explain how self-regulation occurs. Such metacognitive strategies regulate the learning process by orienting, planning, monitoring, and evaluating the learning activity (see, e.g., Veenman and van Cleef, 2019 for an overview of metacognitive strategies). Third, while metacognitive processes indicate how learners regulate their learning, motivational, and emotional processes explain why they do so (Zimmerman and Schunk, 2011). Engaging in monitoring and control is an effortful process that may involve an additional cognitive load to that of the academic task and thus presupposes motivation (Efklides, 2011). Motivation strategies that help to initiate and maintain learning processes refer, for example, to a learner's self-efficacy, one's task value beliefs, and to resource management strategies (see Pintrich, 1999 for an overview). Moreover, a learner's feelings and beliefs result in personal initiative, perseverance, and adaptive behavior (Zimmerman and Schunk, 2011). Beside the regulation of motivation, a learner's regulation of emotions impacts the learning process (Boekaerts, 2002; Ben-Eliyahu, 2019), which can be carried out by applying self-regulated emotion strategies (Ben-Eliyahu and Linnenbrink-Garcia, 2013).

Each of these layers of the construct of self-regulation characterizes a different perspective from which SRL can be conceptualized, which should be combined into a comprehensive concept of SRL (Boekaerts, 1999). Not only researchers but also educators can better use the potential of learning environments that promote SRL when building on a comprehensive notion of self-regulation. A clear conceptualization of SRL is crucial for educators to identify the self-regulatory skills that students need to acquire at each specific moment in their education (Boekaerts, 1999).

\section{Evidence on Teachers' Conceptualization of SRL}

When investigating how educators conceptualize SRL in order to identify their students' level of self-regulation, their professional knowledge comes into play. Teachers' professional knowledge is usually defined as the declarative and procedural knowledge (a) of the teaching content (content knowledge), (b) of how to teach the content to the students (pedagogical content knowledge), and (c) of generic pedagogical knowledge and skills (Shulman, 1987). Educators' conceptualization of SRL draws on generic pedagogical knowledge, whereas their ideas about how to promote SRL may also involve content-specific elements that build on pedagogical content knowledge (Zohar and Schwartzer, 2005). Generic pedagogical knowledge with regard to SRL involves metacognitive knowledge, which consists of knowledge of strategy, task, and person variables (Flavell, 1979), which includes meta-strategic knowledge - i.e., general, explicit knowledge about when, how, and why to use a certain strategy for self-regulating one's learning (Zohar and David, 2008). Evidence about educators' knowledge about self-regulation revealed shortcomings regarding their metacognitive knowledge (Zohar and Lustov, 2018) as well as their meta-strategic knowledge (e.g., Askell-Williams et al., 2012; Glogger-Frey et al., 2018) and their acknowledgment of the functional value of strategies (Kiewra, 2002). When researching their notion of SRL, educators demonstrated higher knowledge about cognitive learning strategies than about metacognitive or motivation strategies (Dignath and Büttner, 2018). On the classroom level, this is reflected in teachers' SRL practice as most students do not learn the conditional knowledge necessary to apply self-regulatory strategies effectively (e.g., Dignath and Büttner, 2018; Zepeda et al., 2019). In general, teachers' ideas about SRL did not necessarily reflect scientific conceptions of SRL (Callan and Shim, 2019). Many teachers rather associate SRL with learning autonomy and self-directedness than with strategic learning processes (Dignath-van Ewijk and van der Werf, 2012; Callan and Shim, 2019).

\section{Promoting Self-Regulatory Skills in the Classroom}

Drawing on scientific models of SRL as described above, supporting students' development of these skills entails that educators promote SRL in their classroom. Several researchers have described characteristics of learning environments that foster self-regulation among learners. Perry $(1998 ; 2013)$, for example, identified four characteristics that activate SRL: First, educators should offer complex and meaningful activities that engage their students in deep learning activities. Second, providing choices - for example, about the learning content, the workplace, or the cooperation partner - supports the learners' feeling of autonomy. Third, educators, who provide choices about the level of the challenge - for example, about how much to work, or at what pace-allow students to develop a better understanding of their own learning processes. Fourth, giving students evaluation criteria activates their skills to reflect on their learning outcomes (Perry, 1998). Similarly, De Corte et al. (2004) derived four characteristics from constructivist learning theory that make learning environments powerful for students' SRL: First, the activation of prior knowledge and the induction of a cognitive conflict can enhance students' engagement in the learning task. Second, learning should be embedded into a meaningful context to increase the learner's effort to transfer the knowledge from the learning situation to a real-life application of the knowledge. Third, providing students with cooperative learning environments encourages students to exchange about different perspectives toward the learning content. Finally, providing students with a semi-structured learning environment allows for effective autonomy and leads to higher self-determination (De Corte et al., 2004). Although these characteristics of powerful learning environments are similar to criteria of teaching quality in general (Seidel and Shavelson, 2007; see Dignath and Veenman, 2020), they have been found to be particularly beneficial to engage students in SRL. However, in how far students can benefit from such learning environments depends on their need for structure and support (Corno, 2008). Corno (2008) describes students' need for support on a support continuum: while the low end of this continuum represents minimal teacher guidance as, for example, found in some of the learning environments described above, the high end of the support continuum represents teaching approaches that provide more structure and guidance, such as in direct instruction (Corno, 2008). Teachers need to know in which situation which of their students need how much support. Moreover, they need to use high-support situations to provide students with the means to 
eventually learn to master low-support learning environments (e.g., Dignath and Veenman, 2020).

Consequently, in order to enact self-regulation, learners do not only need learning environments that provide them with the freedom to engage into self-regulatory processes but also need the necessary skills to regulate their learning effectively (e.g., Paris and Paris, 2001). Educators have been found to be particularly successful in promoting SRL when they also promote self-regulatory strategies in their classroom (e.g., Dignath and Veenman, 2020). This is probably related to the fact that teachers support their students' development of self-regulation through several levels (Zimmerman, 2000, 2002): first, teachers regulate the pacing of learning by demonstrating and verbalizing the enactment of self-regulatory skills explicitly. Second, when students attempt to emulate the enactment of self-regulatory skills, educators can model the behavior by supporting and providing students with feedback. Third, when students have reached a level of self-control, educators can provide students with learning environments that gradually engage them in taking over control for their learning and to deliberately practice the enactment of self-regulatory skills. Finally, when students have reached a level of self-regulation, educators can offer them learning environments without supervision, and the teachers provide assistance only on request (Zimmerman, 2000, 2002). In order to do so, educators have to adapt their learning environments to the self-regulatory level of their students (White and DiBenedetto, 2015). To this end, they first need to identify which self-regulatory strategies students are already able to apply and what they still need to develop (Boekaerts, 1999). Certainly, educators' ability to identify their students' level of self-regulation will be affected by their conceptualization of SRL.

\section{Teachers' Assessment of Students' Learning}

A precondition to adaptive teaching is the assessment of students' learning prerequisites (Brühwiler and Blatchford, 2011). In order to implement microadaptations to each individual in the classroom, educators are continually assessing as they teach (Corno, 2008). Adaptive teachers use the result of this assessment to inform their instructional decisions (Shavelson and Stern, 1981). Consequently, instructional quality varies as a function of teachers' assessment accuracy regarding their students' comprehension (Van de Pol et al., 2010).

\section{Teachers' Need of Diagnostic Cues}

In teaching adaptively, educators need to read students' signals in order to identify their needs (Corno, 2008). For this purpose, educators need to deploy a repertoire of assessment tools to be able to locate each student on the continuum of required support, such as questioning, observing, or interviewing students, as well as written products, oral presentations, projects, tests, or portfolios (Shepard et al., 2005). Which assessment tools they use depends on the type of diagnostic cue that teachers consider in order to judge students' learning (Van de Pol et al., 2019). On which cues teachers base their inferences that they draw about students' learning affects the accuracy of their judgment: judgment accuracy improves when teachers draw their inferences from cues that are particularly diagnostic of students' learning (Brunswik, 1956). For example, a teacher could judge a student's comprehension by the student's correct result in a test, or the teacher could judge the student's comprehension by the student not asking questions during the lesson (see Thiede et al., 2015). Whereas the first cue (the correct test result) is diagnostic of the student's understanding, the second cue (not asking questions) is not. As there are many cues available to judge student learning, it is desirable that educators choose the most diagnostic cues of a certain behavior. Whether teachers focus their attention on more or less diagnostic cues of students' learning depends on teachers' concept of students' comprehension.

\section{Teachers' Assessment of Students' SRL}

With regard to educators' assessment of SRL, little is known yet about the diagnostic cues that they use to take instructional decisions concerning SRL. As one of the few studies investigating teachers' assessment of SRL, Callan and Shim (2019) asked teachers how they identify students with a deficient selfregulation. Most teachers reported to interpret off-task behavior, underachievement, and disengagement as indicators for poor self-regulation. However, these indicators are not very diagnostic of SRL, as the off-task behavior can have many other causes than a deficient SRL. Teachers were less likely to detect specific self-regulation processes as diagnostic cues of deficient SRL (Callan and Shim, 2019). These findings indicate that the teachers may not choose very diagnostic cues of students' self-regulation. This can result in inaccurate judgments about students' self-regulatory skills, and, consequently, in nonadaptive or unsuitable instructional decisions. Another study, which examined teachers' ideas about assessment of SRL, by Michalsky (2017) indicates that teachers hold only limited knowledge about assessment tools to identify students' selfregulatory skills. Based on evidence about SRL assessment (Boekaerts and Cascallar, 2006), she divided assessment tools for SRL into online instruments that assess SRL as an event such as thinking-aloud measures - and into offline instruments that measure SRL as a state - such as strategy questionnaires. Michalsky's (2017) findings showed that most of the teachers, when being asked about how to assess SRL, suggested offline instruments, such as questionnaire or interview, to assess SRL as an aptitude, whereas only $17 \%$ of the teachers suggested to use online instruments that capture SRL as an event. This was also reflected in the teacher survey asking about online and offline assessment tools. Similar results were found when teachers were asked to report about their classroom practice with regard to SRL assessment: two thirds of the teachers described to incorporate offline assessment of SRL as an aptitude, and only one-third to assess SRL as an event. When correlating both measures, only teachers' knowledge about offline assessment was significantly associated with teachers' self-reported assessment behavior. When being asked to define the assessment of learning to learn, $75 \%$ of the teachers focused on the assessment of students' strategy use (i.e., on cues that are diagnostic of SRL), and $28 \%$ focused on the assessment of students domain-related learning achievements, hence, on cues that are less diagnostic of SRL (Michalsky, 2017). Comparing the results of both studies 
presented here, it becomes clear that the findings are inconsistent. Whereas in Callan and Shim's study, teachers reported to use cues that are not diagnostic of SRL, most of the teachers in Michalsky's study focused on cues diagnostic of SRL. Both interview studies provide deep insights into a field that has not been researched before. These first findings indicate a large variation in teacher knowledge about SRL and its assessment. More understanding is needed about factors that explain this variation in how teachers conceptualize SRL and how they diagnose it among their students.

\section{Predictors of Teachers' Judgment Accuracy}

Although research has found teachers' judgment accuracy, in terms of the association between teacher judgment and standardized tests, to be fairly high, teachers' judgment accuracy turned out to vary as a function of teacher characteristics as well as of student characteristics (Südkamp et al., 2012). For example, judgment accuracy was higher for students' academic achievement than for emotional or motivational student characteristics (e.g., Karing, 2009). Furthermore, evidence is inconsistent with regard to the role of teachers' knowledge as a predictor for their judgment accuracy: some findings suggested that teachers' judgment accuracy varies as a function of teachers' knowledge (e.g., Helmke et al., 2004), whereas others did not find an association between teachers' knowledge and their judgment accuracy (e.g., Rausch et al., 2015). Regarding other teacher characteristics, most studies suggested that teaching experience, teacher gender, student age, and student gender did not systematically explain variation in judgment accuracy (e.g., Dicke et al., 2012). Thus, one can conclude that no clear predictors can be identified that explains the variation in teachers' judgment accuracy. Nevertheless, the findings suggest that judgment accuracy varies as a function of different characteristics of students, teachers, and the assessment situation (see Südkamp et al., 2012).

Concerning teachers' assessment of SRL, the two presented studies have investigated some of the teacher characteristics discussed here. Callan and Shim (2019), who compared the overlap of teachers' definitions of SRL with scientific definitions, did not find this overlap to vary as a function of years of teaching experience. Unfortunately, they did not investigate whether teaching experience or teachers' conceptualization of SRL (i.e., the overlap of their definition with the scientific definition) explained variation in teachers' answers regarding the assessment of students' deficient SRL. Likewise, Michalsky (2017) examined whether teachers' self-reported classroom behavior regarding assessment varied as a function of their knowledge about SRL assessment, but she did not test for teacher characteristics to predict teachers' knowledge. Thus, more research is needed to explore how teachers' conceptualization of SRL is associated with teachers' ideas about assessing SRL, and whether both vary as a function of teaching experience.

\section{The Present Study}

One of the most important goals in contemporary education is to support students' development to self-regulating learners (Organisation for Economic Co-operation and Development
[OECD], 2014). The need for students to be able to enact selfregulation during learning has been shown dramatically in the current situation of worldwide school closure to embank the SARS-CoV-2 pandemic. Yet, in order to promote SRL in their classrooms, teachers need to understand the aspects of selfregulation, and they need to identify the self-regulatory skills of their students in order to know where to locate them on the support continuum. The main research question driving this study related to the issue of teachers' conceptualization of SRL and their ideas about assessing SRL in the classroom, as well as associations between both. As only very little research has addressed the important question about teachers' conceptualization of SRL, and only two studies could be identified that have investigated how teachers assess self-regulation, the current interview study was carried out aiming to shed light on teachers' conceptualization and their ideas about assessing SRL by addressing the following research questions:

1. How do teachers conceptualize SRL?

1.1 Which aspects of SRL (cognitive, metacognitive, and motivation/emotion) do teachers know?

1.2 Which moments in the SRL cycle (forethought phase, task performance, and reflection phase) do teachers address?

1.3 Do teachers rather stress the promotion of regulation strategies or student autonomy as characteristic for SRL?

1.4 Which patterns can be derived to describe teachers' conceptualization of SRL?

2. What are teachers' ideas about assessing their students' SRL?
a.
2.1 Do teachers rely on cues that are diagnostic of SRL?
b.
2.2 Which assessment tools do teachers know?

3. Do teachers' ideas about assessing SRL vary as a function of their conceptualization of SRL?

\section{MATERIALS AND METHODS}

\section{Participants}

The study involved 205 in-service teachers, all teaching Grades 1 through 4 in primary school in Germany ${ }^{2}$. Teachers were partly recruited by preservice teachers, who were trained for several hours in conducting the highly structured interviews as part of a teacher education course, partly by contacting schools via email, and partly by posting an invitation to participate in the study in Facebook groups for teachers. All teachers were recruited from different primary schools, covering a large socioeconomic variation in schools. Years of teaching experience for the teachers

\footnotetext{
${ }^{2}$ Note that in most regions in Germany, primary school covers Grades 1 to 4 , and students enter secondary school in Grade 5. Only in few regions in Eastern Germany primary schools involve Grades 5 and 6, but participants in our study did not teach in these regions.
} 
in the study ranged from 1 to 45 years $(\mathrm{M}=14.05, \mathrm{SD}=9.96)$. Teachers' age varied from 24 to 67 years $(M=41.10, \mathrm{SD}=10.92)$. Representational for the population of primary school teachers in Germany, $87 \%$ of the teachers were female. All teachers held a teacher education degree for primary education, which is equivalent to a master's. Participation was voluntary.

\section{Procedure}

We conducted highly structured interviews with 73 teachers that had been recruited by preservice teachers who took a course on SRL as part of initial teacher education. These preservice teachers received extensive training in using a manual to conduct a guided interview with the teachers that took approximately 15 to $20 \mathrm{~min}$. The interviews were audiotaped with the consent of the teachers, and audio-files were transcribed. The remaining 132 teachers answered the open-ended questions online. These teachers were recruited via their schools by email, or via Facebook groups for teachers, and completed an online survey that was constructed with the online survey software EFS Survey (Questback $\mathrm{GmbH}$, 2017). The online survey precisely followed the structure of the guided interview, and teachers spent a comparable amount of time on answering the questions online.

In the next step, the transcribed answers from the teacher interviews as well as the collected teacher answers from the online survey were coded systematically according to a coding scheme. First, we asked teachers about their conceptualization of SRL. As there is a clear scientific definition of the phases of the SRL cycle (see, e.g., Panadero, 2017), we developed a theory-based coding scheme in order to compare teachers' conceptualizations with a scientific SRL concept. This in line with the procedure by Callan and Shim (2019), but our coding scheme differed from their coding as we coded more details of teachers' conceptualization. Additionally, with respect to the different areas of regulation, we coded teacher answers in a data-driven way in order to explore which areas of regulation teachers consider relevant for learning (see, e.g., Boekaerts, 1999). Second, we asked teachers about their ideas about assessing SRL in the classroom. Since there is not a clear scientific conceptualization of SRL assessment in the classroom yet, we derived codes for this question from the empirical data. To this end, 30 teacher interviews were used to collect codes and classify these codes into larger groups. In the next step, these groups were classified into cues that are diagnostic of SRL and cues that are not diagnostic of SRL. This classification was derived from theories on SRL assessment as provided in the literature (e.g., Winne and Perry, 2000; Veenman et al., 2006; Corno, 2008). In the following, both coding schemes will be described more in detail.

\section{Manual of Guided Interview}

To address issues of validity in assessing teachers' conceptualization of SRL and its assessment, we collected the data within naturalistic settings by relating the questions to teachers' own classroom practice. The interviews started by collecting background information of teacher variables, such as age, gender, teaching experience, and prior experiences with SRL. In the next step, we asked teachers to describe in their own words what SRL means. Only after teachers had provided their own conceptualization of SRL were they informed about how we conceptualized SRL in this study in order to provide a joint concept that teachers can base their answers of the following question on. To this end, teachers first received a brief definition of SRL: "Self-regulated learners plan and control their learning independently. To do so, they use learning strategies that help to deal with the larger individual responsibility for their learning effectively." Next, teachers were shown a scheme of the cyclical model of SRL by Zimmerman (2000) that breaks down the SRL cycle into three phases: a forethought phase prior to task performance, a monitoring phase during task performance, and a reflection phase after task performance. The cyclical model was illustrated to teachers with the help of an example. Finally, based on this conceptualization of SRL presented to the teachers, we aimed to register teachers' ideas to assess SRL in the classroom.

\section{Development of the Coding Framework for Teachers' Conceptualization of SRL}

The coding framework for teachers' conceptualization of SRL was developed in an inductive way by analyzing the data for areas of regulation that teachers mention (see Boekaerts, 1999), as well as in a deductive way from a priori categories derived from previous research literature (Mayring and Gläser-Zikuda, 2008). The a priori categories were derived from the cyclical model of SRL by Zimmerman (2000) and the three-layer model of SRL by Boekaerts (1999). This aimed to incorporate significant aspects of the concept of SRL according to the research evidence reviewed in the beginning of this article.

\section{Areas of Regulation}

Beside these process aspects of SRL, self-regulatory actions concern different areas. Learners apply cognitive, metacognitive, and motivation/emotion strategies to support their selfregulation (Boekaerts, 1999). Cognitive aspects of self-regulation that concern the information-processing directly comprise (a) organization strategies that serve to structure and reduce the information, for example, by organizing it into figures, tables, or graphs, and (b) elaboration strategies that serve to extend the information, for example, by linking it to one's prior knowledge or finding examples. Finally, learners apply (c) rehearsal strategies that support memorization of information. All three types of cognitive strategies, although very different by nature, serve to facilitate the information processing (code 4: cognitive). Whereas cognitive strategies are applied mainly during task performance because they proximately concern the processing of the task information, metacognitive and motivation strategies can take place in all three phases of the learning cycle. While the use of cognitive strategies itself is not SRL yet, metacognitive strategies serve to regulate the information processing by planning, monitoring, controlling, and evaluating the learning process. We coded teacher utterances that described metacognitive processes in an abstract way with this code (code 5: metacognitive), whereas all teacher utterances describing regulation processes within the SRL cycle were coded as described above. Because learning also involves emotions and motivation (Efklides, 2011), learners apply motivation strategies to engage into learning prior to task performance, to 
shield one's attention from distractions during task performance, and to attribute one's success or failure after learning (code 6: motivation and motivation). In addition to the three broad categories cognition, metacognition, and motivation and affect derived from the three-layer model (Boekaerts, 1999), we further derived subcodes for the area of motivation and affect in a data-driven way in order to explore which aspects of regulation of motivation and of emotion teachers think of in the context of SRL that we will describe in the section "Results."

Comparable to the phases of the SRL cycle, we also investigated how many teachers referred to all three aspects of the three-layer model of SRL (Boekaerts, 1999). To this end, we grouped all utterances of each teacher together and generated one answer score per teacher by coding whether teachers addressed cognitive, metacognitive, motivational, and emotional aspects of SRL. Thus, we can investigate what percentage of the teachers addressed which aspect of SRL in order to get an overview of how teachers conceptualize SRL.

\section{Three Phases of the SRL Cycle}

The cyclical model involves three phases of self-regulation in the learning process: the forethought phase prior to learning, the monitoring phase during learning, and the reflection phase after learning (Zimmerman, 2000). During the forethought phase, learners plan the learning processes (code 1_1: planning), set goals that they want to reach (code 1_2: goal setting), and prepare the learning environment (code 1_3: preparation). During task performance, learners are using strategies to monitor and control their learning progress. This serves to adapt one's actions to the requirements in order to reach the goal (code 2_1: monitoring). Moreover, a learner organizes one's time and monitors the available time (code 2_2: time management), as well as the available resources and one's own endurance to finish the task (code 2_3: available resources). After learning, the learners check whether their results are aligned with the objectives (code 3_1: alignment with objectives), they reflect on what went well during the learning process and what has to be improved next time (code 3_2: reflection), and they draw inferences from these findings for the following learning cycle (code 3_3: feedback loop).

Each single teacher utterance was coded. For the analyses, we counted each code only one time per teacher and computed frequencies for each single code. Each code is part of a category and can be grouped within this category. For example, if we assigned the code 1_1 "planning" to a teacher utterance, this code belongs to the category "forethought phase" within the SRL cycle (see Table 1 for the coding scheme of teachers' conceptualization of SRL). Each code can be examined separately, but codes that belong to one category can also be combined to examine how often each category was addressed. Moreover, we generated a score of model integrity to assess whether teachers conceptualized SRL according to the entire SRL cycle, thus mentioning all three phases of the SRL cycle (Zimmerman, 2000).

\section{Self $=$ Self-Directedness or Regulation $=$ Regulatory Processes of Learning?}

As previous research has shown, many teachers do not associate SRL directly with learners' self-regulatory processes but rather with self-directed learning and autonomous learning environments (e.g., Dignath-van Ewijk and van der Werf, 2012; Callan and Shim, 2019). In order to capture whether teachers conceptualize SRL mainly as a self-directed learning environment or as a strategic learning process, we coded whether teachers focused on strategic learning behavior, self-regulatory skills, or teachers' promotion of self-regulatory strategies (code 7_1) or/and on the individual responsibility of the student, the selfdirectedness of learning, the learning autonomy, or the idea that the teacher should keep out of the learning process during SRL (code 7_2 [e.g., "In SRL, students take over the responsibility for their learning and take all the decisions by themselves."]).

For the final coding framework, we formulated operational definitions of each of the categories, together with examples taken from the teacher answers to illustrate each code. First, we tested the developed coding scheme with the answers of 30 interviewed teachers in order to improve the operational definitions until the codes were mutually exclusive and exhaustive. Next, 200 utterances of teacher answers were dual-coded by two raters independently, and interrater reliabilities were calculated. The analyses of interrater agreement, carried out by computing the Cohen's kappa, was satisfactory $(\kappa=0.85, S E=0.03)$. Table 1 provides the final coding framework with operational definitions and examples from teacher answers for each code.

\section{Coding of Teachers' Ideas About Assessing SRL}

As there are no theoretical models available about teachers' assessment of SRL in the classroom, this coding framework was developed in an inductive way from categories derived from the data. First, we conducted in-depth interviews with two primary school teachers to examine their ideas about assessing SRL. Based on their answers, we formulated three questions that served to address teachers' notion of SRL assessment: (1) How do you assess the self-regulatory skills of your students? (2) How do you identify which strategies your students know and use in order to regulate their learning? (3) How do you register your students' progress in regulating their own learning? In the second step, we applied these questions in highly structured interviews with 26 teachers after having informed them about our scientific understanding of SRL (see section "Manual of Guided Interview"). From these answers, we obtained 235 teacher utterances that were transcribed and coded into 30 categories. Based on previous research about SRL assessment (Veenman and van Cleef, 2019), we sorted these 30 categories into three groups of assessment instruments: prospective off-line (e.g., reflective talk with the students), simultaneous on-line (e.g., observation of student behavior), and retrospective off-line instruments (e.g., completing a portfolio or learning diary). Moreover, we grouped the codes into categories about the diagnosticity of cues: cues that are diagnostic of SRL (e.g., student's reflection in a learning diary) and cues that are less diagnostic of SRL (e.g., students' off-task behavior). In the third step, we conducted cognitive interviews with six primary school teachers who judged the importance of our derived codes. Based on their input, the coding categories were refined, the number of codes was reduced, and 
TABLE 1 | Coding manual for teachers' conceptualization of SRL with examples per code.

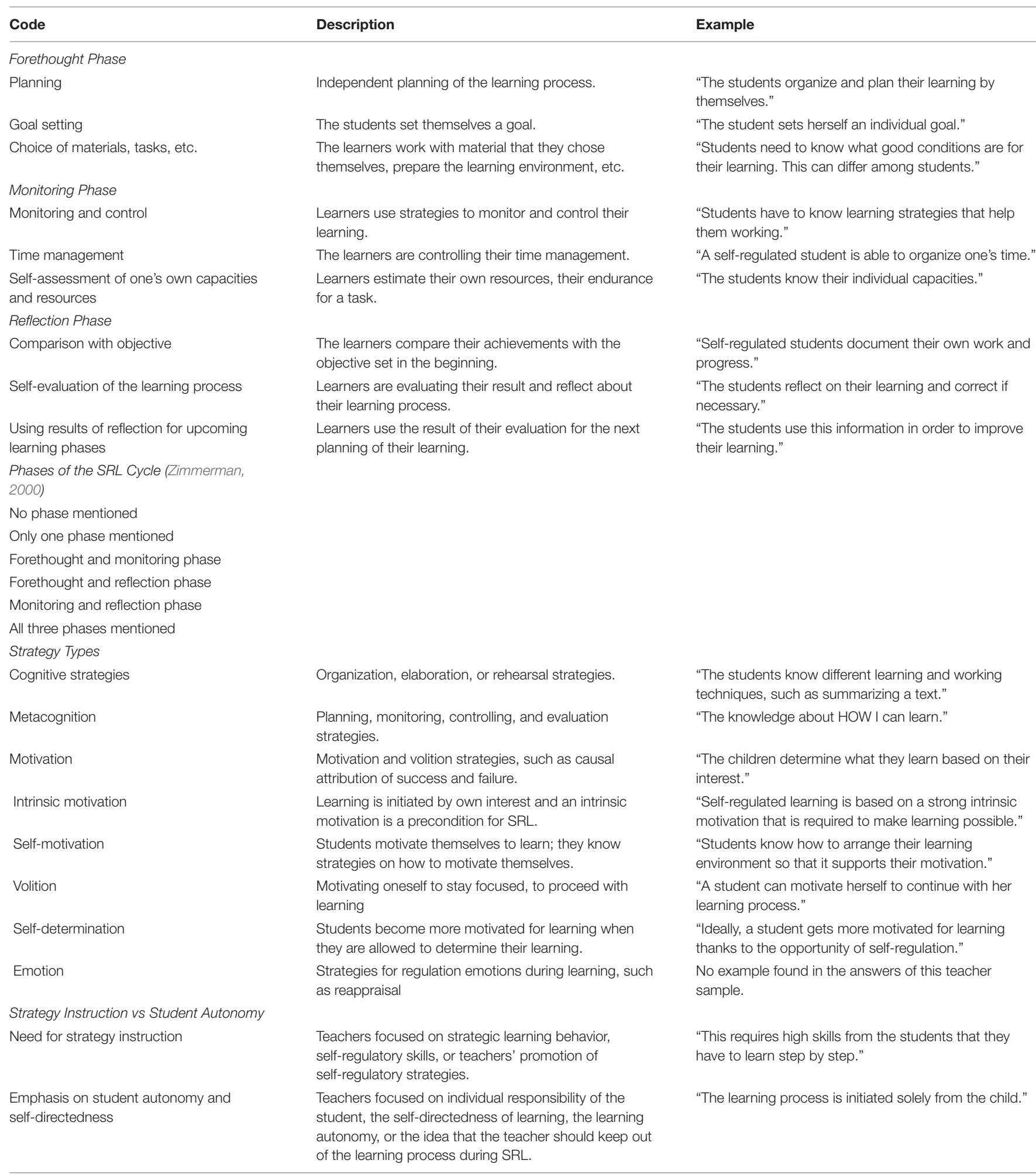

the discriminatory power of codes was optimized. For this final coding framework, we formulated operational definitions of each of the categories, together with examples taken from the teacher answers to illustrate each code. The refined coding framework was applied to the 235 teacher utterances by two independent coders. Interrater reliability was acceptable $(\kappa=0.63, S E=0.05)$. Table 2 provides the final coding framework with operational definitions and examples from teacher answers for each code. 
TABLE 2 | Answering codes for teachers' ideas about assessing SRL.

\begin{tabular}{|c|c|c|}
\hline Code & Description & Example \\
\hline \multicolumn{3}{|l|}{ Cues used for Assessment } \\
\hline $\begin{array}{l}\text { Evaluation of students' } \\
\text { self-assessment }\end{array}$ & $\begin{array}{l}\text { Students' choice of challenge; written or } \\
\text { oral self-assessment }\end{array}$ & $\begin{array}{l}\text { "For example, I observe which assignment } \\
\text { they choose." }\end{array}$ \\
\hline Observation of off-task behavior & Off-task, inappropriate behavior & $\begin{array}{l}\text { "These children that I have to supervise } 4-5 \\
\text { times per lesson because they just do not } \\
\text { work. You always have to be close to their } \\
\text { table, they are just not doing anything by } \\
\text { themselves." }\end{array}$ \\
\hline $\begin{array}{l}\text { Cues from achievement that } \\
\text { hint to strategy use }\end{array}$ & $\begin{array}{l}\text { Assignments that require the use of certain } \\
\text { strategies or checklists about finished } \\
\text { assignments }\end{array}$ & $\begin{array}{l}\text { "For some assignments, the students are } \\
\text { required to use strategies in order to be } \\
\text { able to solve them." }\end{array}$ \\
\hline Academic achievement & & $\begin{array}{l}\text { "I check whether the children have } \\
\text { understood the learning content. Do they } \\
\text { know the basics at least?" }\end{array}$ \\
\hline \multicolumn{3}{|l|}{ Means of Assessment } \\
\hline $\begin{array}{l}\text { Assessment by means of } \\
\text { instruments }\end{array}$ & $\begin{array}{l}\text { Teacher uses any kind of standardized } \\
\text { instrument to assess SRL (e.g., portfolio, } \\
\text { learning diary, and strategy questionnaire) }\end{array}$ & $\begin{array}{l}\text { "In one classroom, I had my students fill in a } \\
\text { reading diary. This also shows how } \\
\text { self-regulated they are." }\end{array}$ \\
\hline Reflective talk & $\begin{array}{l}\text { Single talk with individual students or group } \\
\text { talk with the whole class about learning } \\
\text { behavior }\end{array}$ & $\begin{array}{l}\text { "I ask each student: How did you find this } \\
\text { result?" }\end{array}$ \\
\hline Unsystematic observation & $\begin{array}{l}\text { Spontaneous observation in the classroom } \\
\text { of vague student activities }\end{array}$ & $\begin{array}{l}\text { "I just feel how my students can learn. } \\
\text { Honestly, if you are teaching in a classroom, } \\
\text { after a while you know your students." }\end{array}$ \\
\hline Systematic observation & $\begin{array}{l}\text { Observation of students' learning activities } \\
\text { by means of an observation scheme }\end{array}$ & $\begin{array}{l}\text { "I am using my observation sheet and } \\
\text { observe 2-3 children per lesson." }\end{array}$ \\
\hline
\end{tabular}

\section{Statistical Analyses}

In the first step, we examined the frequencies of teacher answers for each single code. Moreover, we grouped single codes according to the coding scheme in groups as described above. With the aim of detecting systematic associations between teachers' conceptualization of SRL and their ideas about how to assess SRL, we computed correlations among the codes of both constructs. Moreover, we used cluster analysis to detect patterns of teachers' conceptualization of SRL and grouped these into clusters. We submitted the data to cluster analysis in order to group similar conceptualization of SRL in the dataset such that teachers' conceptualization in the same group are similar to each other, and, similarly, teachers' conceptualization in different groups are as different to each other as possible. We used the two-step clustering algorithm in SPSS to identify clusters of SRL conceptualizations among the 205 teachers. This algorithm is designed to handle both continuous and categorical variables and identifies the optimal number of clusters empirically rather than a priori (IBM Corp, 2016). The distance between two clusters is defined as the corresponding decline in log-likelihood by combining them together. In the first step of the procedure, the cases are sorted into pre-clusters. In the second step, the preclusters are clustered using a hierarchical clustering algorithm. Based on the Bayesian information criterion, the most fitting cluster solution is selected (Banfield and Raftery, 1993). Finally, we investigated whether teacher answers about ideas to assess SRL varied as a function of teachers' belonging to a certain cluster. To this end, we performed a Kruskal Wallis test with the cluster membership as group variable for the assessment codes.

\section{RESULTS}

\section{How do Teachers Conceptualize SRL? Which Aspects of SRL (Cognitive, Metacognitive, Motivation, and Emotion) do Teachers Mention When Defining SRL? \\ In accordance with the coding scheme, we coded teacher} utterances that described cognitive, metacognitive, motivational, or affective processes. For instance, a teacher answer describing as characteristic of SRL that "a self-regulated student knows how to extract the most important information from a text" was coded as cognition, whereas a teacher answer conceptualizing SRL "as a student's knowledge about the requirements of learning successfully" was coded as metacognition. Hardly $10 \%$ of the teachers described cognitive strategies as characteristics of SRL. Only $5 \%$ of the teacher answers were coded as metacognitive; however, the teacher utterances that were coded according to the SRL cycle (see next subchapter) are certainly referring to metacognitive processes as well. Taking them all together yields that nearly $75 \%$ of all teachers addressed metacognition when conceptualizing SRL (see Table 3). The remaining $25 \%$ of the teachers did described neither metacognitive activities on an abstract level nor more precise regulation activities that were coded as part of the SRL cycle. Almost one fourth of the teachers mentioned students' motivation as important part of SRL. We found teacher answers from this category (code 6) to decompose into four subareas of regulation. (1) Intrinsic motivation (code 6_1): Learning is initiated by the learner's own interest. Thus, the learner's intrinsic motivation is a precondition for SRL. Most 
TABLE 3 | Frequencies of codes for teacher utterances about defining SRL.

\begin{tabular}{lcc}
\hline Code & Frequency & Percentage \\
\hline Forethought Phase & 128 & 62.4 \\
Planning & 42 & 20.5 \\
Goal setting & 32 & 15.6 \\
Choice of materials, tasks, etc. & 91 & 44.4 \\
Monitoring Phase & 57 & 27.8 \\
Monitoring and control & 24 & 11.7 \\
Time management & 21 & 10.2 \\
Self-assessment of one's own & 22 & 10.7 \\
capacities and resources & & \\
Reflection Phase & 42 & 20.5 \\
Comparison with objective & 14 & 6.8 \\
Self-evaluation of the learning process & 28 & 13.7 \\
Using results of reflection for upcoming & 10 & 4.9 \\
learning phases & &
\end{tabular}

Phases of the SRL Cycle

(Zimmerman, 2000)

No phase mentioned

Only one phase mentioned

Forethought and monitoring phase

Forethought and reflection phase

Monitoring and reflection phase

All three phases mentioned

Strategy Types

Cognitive strategies

Metacognition

Motivation

Intrinsic motivation

Self-motivation

Volition

Self-determination

Emotion

Strategy Instruction vs. Student

Autonomy

Need for strategy instruction

Emphasis on student autonomy and

self-directedness

Percentage does not sum up to $100 \%$ as teachers' answers received more than one code. Every teacher answer received each code not more than one time.

teacher utterances $(N=29)$ that addressed motivation focused on this subarea. (2) Self-motivation (code 6_2): Students need to know how to motivate themselves to learn. They know strategies on how to motivate themselves. This subarea of self-motivation was mentioned by 12 teachers. (3) Volition (code 6_3): The third subarea refers to volition; i.e., a learner's motivation and attention that serves to stay focused and to proceed with learning. Two teachers referred to this subarea. (4) Self-determination (code 6_4): The last subarea that we detected in the teacher data referred to self-determination, meaning that students become more motivated for learning when they are allowed to determine parts of their learning. Four teachers mentioned self-determination in their answer. (5) Emotion (code 6_5): Although a learner's regulation of academic emotions plays an important role for learning (e.g., Pekrun, 2006; Ben-Eliyahu, 2019), none of the teachers in our sample mention emotions or anything related to the regulation of affect.

\section{Which Moments in the SRL Cycle (Forethought Phase, Task Performance, and Reflection Phase) do Teachers Address?}

The codes capturing aspects of the SRL cycle were grouped according to the three phases of the cycle. Most teachers referred to self-regulatory processes in the forethought phase (62\%). More precisely, $44 \%$ of the teachers explained that SRL entails the students choosing their own materials or having choices about where to work, with whom, or at which pace (see Table 3). Less often, teachers mentioned a student's planning activities $(21 \%)$, or their goal setting (16\%). The second most occurring phase was the monitoring phase (28\%). Within this phase, approximately $10 \%$ of the teachers conceptualized SRL each as students' reflection about their own capacities (e.g., "recognizing one's own knowledge gaps" or "strengths and weaknesses") - this was often about students' self-estimation of the suitable level of challenge when choosing an assignment or learning material or as monitoring and control of learning (e.g., "Students use strategies to control their learning."), or as time management. Only $20 \%$ of teachers referred to the reflection phase. Within this phase, $14 \%$ of the teachers addressed the evaluation of the learning process (e.g., "Students reflect about their learning."), but only 7\% mentioned to check whether the goal was met (e.g., "A self-regulated learner checks whether the result is aligned with her objectives."), and only $5 \%$ suggested to use the results of this reflection to improve future learning (see Table 3 ).

Two thirds of the teachers' answers about describing SRL were assigned to codes from one single phase of the SRL cycle only. Some of the teacher answers combined the forethought phase with the monitoring phase $(16 \%)$ or the reflection phase (11\%), and only four teachers addressed the monitoring and the reflection phase $(2 \%)$. Only seven teachers $(3 \%)$ referred to all three phases of the SRL cycle. One fourth of all teachers' answer could not be assigned to any of the codes of the SRL cycle. Among these 52 teachers, the answers of 44 teachers also did not address metacognitive activity in a more general way.

\section{Do Teachers Rather Stress the Regulatory Processes or Student Autonomy as Characteristic for SRL?}

Based on the results by Callan and Shim (2019), which had shown that most teachers described SRL as student directness rather than addressing regulation processes, we coded whether teachers emphasized student autonomy as a main feature of SRL. In addition, we added a code to capture whether teachers reported about regulation procedures that students have to learn. In line with Vosniadou et al. (2020), we assume that teachers can hold inconsistent beliefs about SRL. Consequently, both codes were not mutually exclusive. As the results show, only nineteen teachers mentioned that self-regulated learners need strategies that they had to acquire at some time. In contrast, $40 \%$ of all teachers emphasized students' autonomy and self-directedness as characteristic for SRL. For 21 teachers, their whole answer to this question was solely based on this assumption (i.e., they received only the code student autonomy). Among the nineteen teachers, 


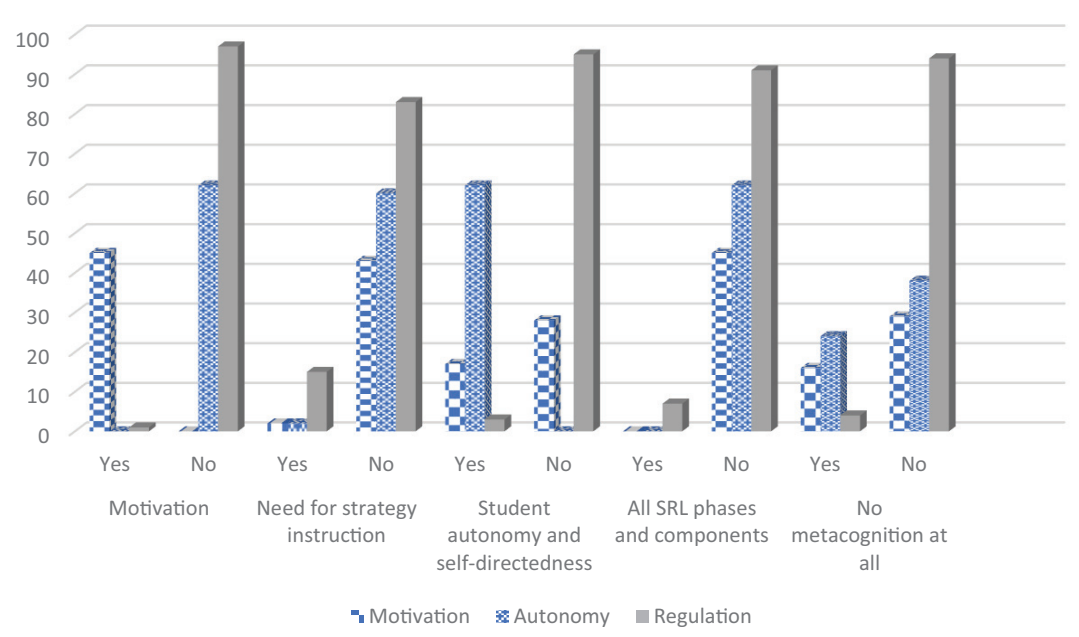

FIGURE 1 | Patterns of SRL conceptualization for the three cluster groups as a result of the two-step cluster analysis. Columns represent frequencies of codes of the 205 teachers sorted per cluster group.

who stressed that students had to learn self-regulation strategies before being able to self-regulate, six teachers also focused on student autonomy. Moreover, most of these teachers suggested regulation strategies that belonged to one single phase of the SRL cycle, whereas four teachers also stressed the forethought and the monitoring phase, and one teacher addressed all three phases of the SRL cycle.

\section{Which Patterns of Teachers' Conceptualization of SRL Can Be Found?}

In order to determine patterns of teachers' ideas about SRL, we submitted the data to a two-step cluster analysis that was based on teachers' answers about conceptualizing SRL. To this end, the following variables capturing teachers' knowledge about SRL were entered to derive the cluster: (1) the number of phases from the SRL cycle, (2) whether teachers mentioned all three areas of regulation, (3) whether teachers also focused on motivation, (4) an emphasis on student autonomy and self-directedness, and (5) the need for strategy instruction. The cluster analysis revealed three patterns (see Figure 1).

\section{SRL as motivation}

The teacher answers in cluster $1(N=45,22 \%)$ focused on motivation as most important component of SRL (97.8\%). These teachers were less likely to focus on the need for instructing strategies (10.5\%) or on students' autonomy and self-directedness $(20.7 \%)$ and were diverse in terms of referring to metacognitive and regulatory processes or not. On average, these teachers referred to the lowest number of phases from the SRL cycle $(M=0.24, S D=0.61)$. As this cluster is most distinctive based on the strong reference to motivation, cluster 1 will be called motivation.

\section{SRL as autonomy}

The teacher answers in cluster $2(N=62,30.2 \%)$ did not refer to motivation at all (0\%) and were also not likely to refer to students' need to learn regulation strategies (10.5\%). Yet, these teachers mainly focused on student autonomy and selfdirectedness $(75.6 \%)$. Teachers in this cluster were more likely not to refer to metacognitive processes at all than teachers in the other two clusters (54.5\%). Like the teachers in cluster 1, these teachers addressed only few phases of the SRL cycle $(M=0.29$, $S D=0.66)$. Their main characteristic is their strong emphasis on student autonomy and self-directedness when conceptualizing SRL, and this cluster is therefore called autonomy.

\section{$S R L$ as regulation}

Finally, the teachers in cluster $3(N=98,47.8 \%)$ were not likely to emphasize motivation when describing SRL (2.2\%); neither was student autonomy (3.7\%). Teachers in this cluster were more likely to stress the need to instruct regulation strategies for SRL (78.9\%) compared to the other two clusters, and teachers in this cluster were most likely to refer to all SRL phases and components in their description (100\%). Only very few teachers in this cluster had not addressed metacognitive processes in their description of SRL (9.1\%). On average, these teachers referred to the highest number of phases from the SRL cycle $(M=0.92, S D=1.20)$. Due to this emphasis on regulation processes, this cluster is called regulation.

On a descriptive level, teachers who were assigned to the cluster autonomy were on average two years older and had one more year of teaching experience than the teachers from the other two clusters. However, these differences between the cluster groups were not significant (see Table 4).

\section{What Are Teachers' Ideas About Assessing Their Students' SRL?}

We examined teachers' ideas about assessing SRL in the classroom by analyzing teachers' answers according to our coding scheme (see Table 2). We will first present the descriptives of all codes about cues used for assessment grouped within answering categories. Next, we will describe the assessment tools that teachers reported to use. 
TABLE 4 | Teacher characteristics of the three cluster groups (M and SD).

\begin{tabular}{lccc}
\hline & \multicolumn{3}{c}{ Cluster } \\
\cline { 2 - 4 } & $\mathbf{1}$ & $\mathbf{2}$ & $\mathbf{3}$ \\
\hline $\mathbf{N}$ & $\mathbf{4 5}$ & $\mathbf{6 2}$ & $\mathbf{9 8}$ \\
\hline Age & $40.82(11.06)$ & $42.11(10.90)$ & $40.60(10.95)$ \\
Work experience as teacher & $13.32(9.64)$ & $14.68(9.89)$ & $13.96(10.21)$ \\
Number of phases of SRL cycle & $0.24(0.61)$ & $0.29(0.66)$ & $0.92(1.20)$ \\
\hline
\end{tabular}

$M=$ mean,$S D=$ standard deviation

\section{Do Teachers Rely on Cues That Are Diagnostic of SRL?}

Teachers' answers were rather unprecise regarding the type of cues that they use to assess the SRL of their students. Most often, teachers reported to evaluate students' self-assessment in order to diagnose how self-regulated students are $(42 \%)$. This includes, for example, teachers' observation of the students' choice for challenge when students can choose the assignment themselves, or any kind of written or oral self-assessment in the classroom (e.g., "My students have to fill in a checklist when working with a weekly planning in order to indicate which assignments they have finished."). As the second most occurring, 39\% of the teachers reported to rely on students' off-task behavior in the classroom in order to diagnose how self-regulated a student can learn (e.g., "When you see that a student has tried to work on an assignment but does not manage to proceed, then you can see that it does not work."). Moreover, this can also refer to students' inappropriate behavior when working on an assignment. With regard to students' learning results, $20 \%$ of the teachers described to retrieve information about students' SRL from the achievement outcome that would be regarded as a cue for students' strategy use. For example, some teachers report to give assignments that students can only solve when applying certain strategies (e.g., "I developed this assignment that they [the students] can only manage when they have these competencies, and when they finish the assignment, then I know that they must have these competencies."). Finally, $11 \%$ of the teachers said to derive conclusions about students' SRL from their academic achievement, i.e., the learning output (e.g., "I look at the learning progress of a student during an exam. This shows me whether a student had been able to self-regulate her learning or not.").

\section{Which Assessment Tools do Teachers Know?}

More than half of the teachers indicated to use portfolio or learning diaries in order to assess how their students can selfregulate their learning (see Table 5). However, only very few teachers have elaborated on the specific cues that they take into account in a portfolio or learning diary (e.g., "My students are supposed to complete a learning diary, and I check which objectives students set themselves and if they pursue these objectives appropriately."). More often, teachers did not specify the indicators in students' answers of a portfolio or learning diary that serve as cues for SRL (e.g., "Progress is registered in a learning diary."). Next, $34 \%$ of the teachers described to do reflective talks with single students or the whole group of students
TABLE 5 | Frequencies of codes for teachers' ideas about assessing SRL.

\begin{tabular}{lcc}
\hline Code & Frequency & Percentage \\
\hline Cues used for Assessment & & \\
Evaluation of students' self-assessment & 85 & 41.5 \\
Observation of off-task behavior & 80 & 39 \\
Cues from achievement that hint to strategy use & 41 & 20 \\
Academic achievement & 22 & 10.7 \\
Means of Assessment & & \\
Assessment by means of instruments (e.g., portfolio) & 114 & 55.6 \\
Reflective talk & 70 & 34 \\
Unsystematic observation & 27 & 13.2 \\
Systematic observation & 24 & 11.7
\end{tabular}

Percentage does not sum up to $100 \%$ as teachers' answers received more than one code. Every teacher answer received each code not more than one time.

in order to find out how students proceeded during learning (e.g., "I ask my students to describe what they did to solve the problem.") or to evaluate how their learning process went (e.g., "After the learning phase, I reflect with my students about the methods used."). From the $24 \%$ of teachers, who indicate to use observation as a method to assess SRL, half of the teachers specify to use systematic observations (e.g., "I use observation sheets to document students' working and learning behavior."), whereas the other half applies observation in an unsystematic way (e.g., "I observe in my classroom how a student is working.").

\section{Do Teachers' Ideas About Assessing SRL Vary as a Function of Their SRL Concepts?}

Finally, we combined the data about teachers' conceptualization of SRL with their ideas about SRL assessment. To this end, we first computed correlations between teachers' conceptualization of SRL and their ideas about assessing SRL. Next, to investigate whether teachers' ideas about SRL assessment varied as a function of the cluster belonging, we submitted the data to a Kruskal Wallis test.

\section{Associations Between Teachers' SRL Concepts and Their Ideas About SRL Assessment}

Spearman correlations indicated that teachers, who described SRL as regulation of motivation, less often reported to assess SRL by means of observing off-task behavior, $r=-0.14, p=0.04$ (see Table 6). Moreover, we found teachers' conceptualization of SRL as student-directed and autonomous learning to be associated with teachers assessing SRL by interpreting learning outcomes that hint to strategies being used, $r=0.16, p=0.02$, by holding reflective talks, $r=0.15, p=0.04$, and by conducting unsystematic observation, $r=0.18, p=0.01$. Teachers, who described SRL by addressing regulation processes of the forethought phase, were more likely to report that they use students' achievement outcomes as cues for diagnosing SRL, $r=0.19$, $p=0.01$. Teacher answers referring to the monitoring phase were associated with teachers reporting to use portfolio to assess SRL, $r=0.20, p<0.001$. 
TABLE 6 | Spearman correlations between codes of SRL conceptualization and codes of ideas about SRL assessment, $r(p)$.

\begin{tabular}{|c|c|c|c|c|c|c|c|c|}
\hline & Self-ass. & Off-task & Strat. hint & Achiev. & Reflective & Portfolio & $\begin{array}{l}\text { Unsystem. } \\
\text { observation }\end{array}$ & $\begin{array}{l}\text { Systematic } \\
\text { observation }\end{array}$ \\
\hline Cognitive & $-0.11(0.12)$ & $0.04(0.57)$ & $0.08(0.24)$ & $-0.06(0.39)$ & $0.01(0.93)$ & $0.06(0.38)$ & $-0.13(0.07)$ & $0.08(0.23)$ \\
\hline Metacognitive & $0.02(0.78)$ & $0.08(0.28)$ & $0.04(0.54)$ & $-0.08(0.24)$ & $-0.08(0.25)$ & $-0.05(0.49)$ & $0.04(0.62)$ & $0.05(0.49)$ \\
\hline Motivation & $0.00(0.98)$ & $-0.14^{\star}(0.04)$ & $-0.01(0.93)$ & $-0.04(0.61)$ & $0.11(0.13)$ & $-0.01(0.85)$ & $-0.07(0.31)$ & $-0.05(0.47)$ \\
\hline Strategy instr. & $0.00(0.95)$ & $0.05(0.44)$ & 0.09 (0.19) & $0.05(0.46)$ & $0.12(0.08)$ & $0.12(0.10)$ & $-0.02(0.72)$ & $-0.01(0.87)$ \\
\hline Autonomy & $-0.02(0.77)$ & $0.12(0.08)$ & $0.16^{\star}(0.02)$ & $0.10(0.14)$ & $\mathbf{0 . 1 5 *}(0.04)$ & $0.03(0.69)$ & $0.18^{\star \star}(0.01)$ & $-0.08(0.25)$ \\
\hline Forethought & $0.08(0.28)$ & $0.01(0.85)$ & $0.07(0.30)$ & $0.19^{\star \star}(0.01)$ & $0.07(0.34)$ & $-0.08(0.24)$ & $-0.04(0.56)$ & $0.05(0.52)$ \\
\hline Monitoring & $-0.02(0.73)$ & $0.05(0.48)$ & $0.13(0.07)$ & $0.05(0.45)$ & $-0.08(0.25)$ & $\mathbf{0 . 2 0 * *}(<0.001)$ & $-0.03(0.71)$ & $0.05(0.47)$ \\
\hline Reflection & $-0.08(0.25)$ & $-0.13(0.06)$ & $-0.02(0.74)$ & $-0.06(0.36)$ & $0.10(0.17)$ & $-0.02(0.73)$ & $-0.06(0.38)$ & $-0.08(0.27)$ \\
\hline Number of phases & $-0.06(0.41)$ & $-0.03(0.69)$ & 0.07 (0.32) & $0.03(0.69)$ & 0.00 (0.99) & $-0.05(0.45)$ & $-0.05(0.49)$ & $0.02(0.78)$ \\
\hline
\end{tabular}

$r=$ correlation coefficient, Cognitive = cognitive strategies, Metacognitive = metacognitive strategies, Motivation = motivation strategies, Strategy instr. = strategy

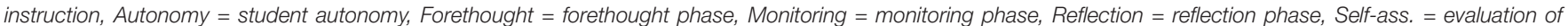
students' self-assessment, Off-task = observation of off-task behavior, Strat. hint = cues from achievement that hint to strategy use, Achiev. = academic achievement, Reflective $=$ reflective talk, Unsystem. observation $=$ Unsystematic observation. Significant correlations are bold. ${ }^{* *}$ Significant with $p>0.05,{ }^{* *}$ significant with $p<0.01$.

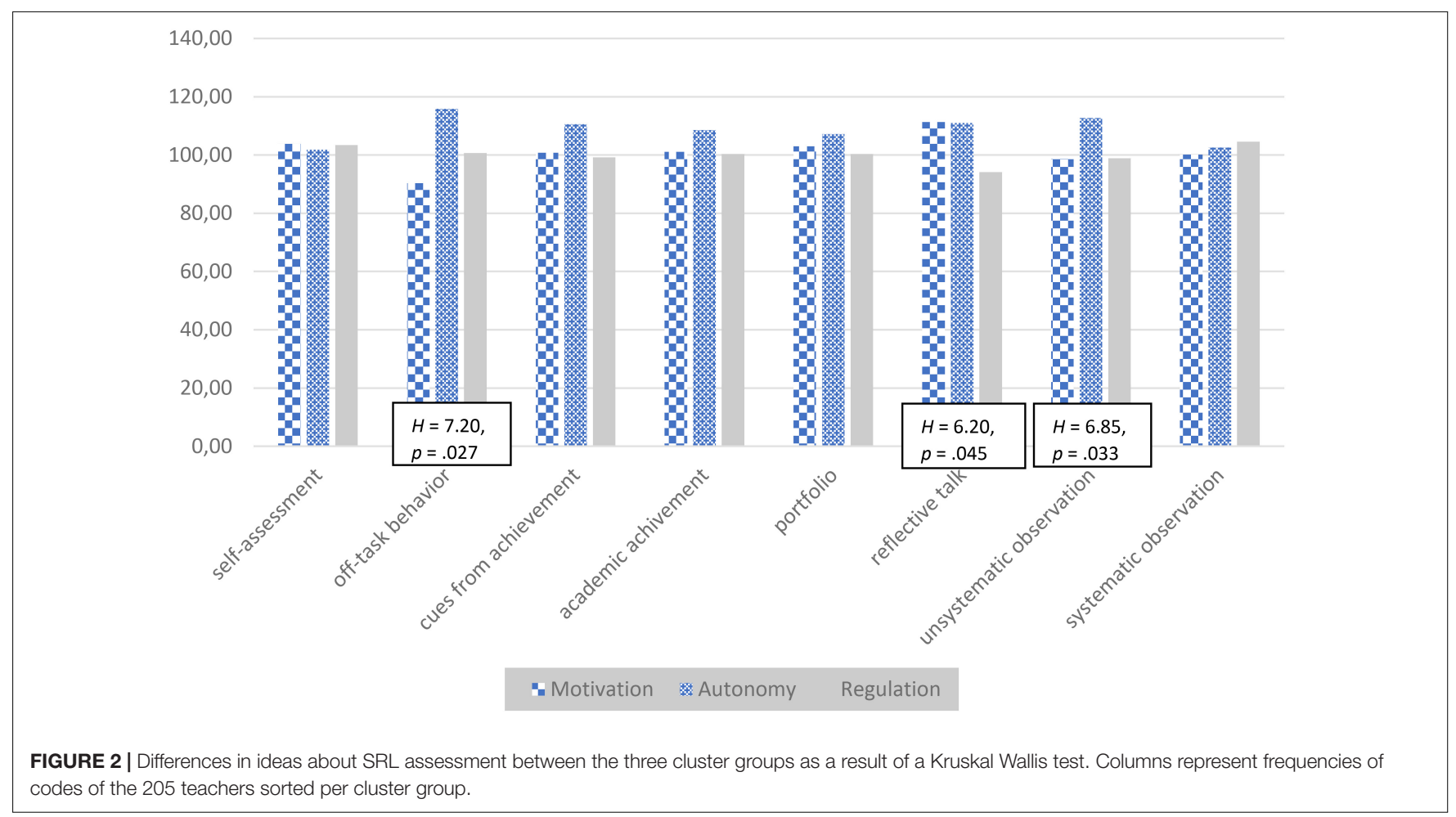

\section{Differences Based on Cluster Membership}

When comparing teachers' ideas about assessing SRL between the three clusters, we found significant differences between the cluster groups for the variables unsystematic observation, off-task behavior, and reflective talk (see Figure 2). Teachers from the autonomy cluster reported significantly more often to use unsystematic observations to assess self-regulation in the classroom than the teachers from the other two clusters, $H=6.85$, $p=0.03$, as well as to use students' off-task behavior as a cue to diagnose self-regulation, $H=7.20, p=0.03$. Moreover, teachers from the regulation cluster applied significantly less often reflective talk with students to assess their self-regulation than teachers from the other two clusters did, $H=6.20$, $p=0.045$. For the other categories, we did not find any significant differences between the cluster groups. On a descriptive level, teachers from the autonomy cluster reported to use information from students' learning products or from students' academic achievement as cue to diagnose self-regulation more often than the teachers from the other two clusters (see Figure 2).

\section{DISCUSSION}

We investigated among 205 teachers how they conceptualized SRL, what their ideas were about assessment of SRL in the classroom, and whether teachers' SRL assessment varied as a function of their SRL conceptualization. First, with regard to their SRL conceptualization, one fourth of all teachers did not refer to any regulation procedure at all, and $40 \%$ of the teachers described SRL as student autonomy and self-directedness. Thus, 
although many teachers think of regulation procedures when conceptualizing SRL, only a few teachers have a comprehensive conception of the entire SRL cycle. Second, with regard to the area of regulation, many teachers associated SRL with the regulation of cognitive and metacognitive aspects as well as with the regulation of motivation. However, no teacher in our sample referred to the regulation of emotions. Third, the current study identified three patterns of teachers' conceptualizations of SRL: a motivation-oriented conceptualization of SRL, an autonomyoriented conceptualization of SRL, and a regulation-oriented conceptualization of SRL. Fourth, with regard to teachers' ideas about assessing their students' SRL, we found teachers to mainly focus on cues that are not necessarily diagnostic of SRL, but many teachers knew about portfolios or learning diaries to register SRL among students. Finally, our results suggest that, partly, teachers' ideas about assessing SRL vary as a function of their SRL concept: teachers with an autonomy-oriented conceptualization of SRL are more likely to use cues that are not diagnostic of SRL, such as unsystematic observation or off-task behavior.

Consistent with other research, teachers' conceptualization of SRL differed from a scientific SRL concept (Zohar and Lustov, 2018; Callan and Shim, 2019). More specifically, our results showed that most teachers conceptualized SRL as regulation procedures taking place in the forethought phase of the SRL cycle, whereas only a few teachers also addressed regulation processes from the monitoring or the reflection phase. Contrary to this result, other studies that examined teachers' SRL practice in the classroom indicated that most teachers did not address regulation strategies of the forethought phase (e.g., Kistner et al., 2010), but rather strategies of the monitoring phase (e.g., Spruce and Bol, 2015), or of the reflection phase (e.g., Zepeda et al., 2019). The question arises in how far teachers' conceptualization of SRL is reflected in their SRL practice.

Besides the deductive coding of teacher answers in comparison to a scientific SRL concept, we explored which areas of regulation teacher associate with SRL, revealing that teachers mainly referred to regulation of cognition and behavior, and to regulation of motivation, in particular, intrinsic motivation. Although the regulation of motivation plays an important role for learning, regulating one's emotions has major effects on learning as well (Pekrun, 2006; Ben-Eliyahu and Linnenbrink-Garcia, 2013; Ben-Eliyahu, 2019) as academic emotions are related to students' motivation, their use of learning strategies, and their cognitive resources (Pekrun et al., 2002). Yet, the regulation of emotions in the context of SRL seems to be a neglected area by practitioners.

In contrast to this explorative finding, we could replicate the commonly discovered finding that teachers only rarely teach regulation strategies explicitly (e.g., Bolhuis and Voeten, 2001; Kistner et al., 2010; Dignath-van Ewijk et al., 2013; Dignath and Büttner, 2018) also on the level of teachers' conceptualization of SRL: many teachers focused rather on student autonomy and self-directedness of learning, but only a small share of teachers described that students need to learn regulation strategies for SRL. This was also reflected in the patterns of SRL concepts found in this study and is consistent with other studies which indicated that many teachers consider SRL to be a self-directed process rather than a regulation process (e.g., Dignath-van Ewijk and van der Werf, 2012; Callan and Shim, 2019; Lawson et al., 2019).

Like in previous research about teachers' ideas to assess SRL (Callan and Shim, 2019), most of the cues mentioned by the teachers in our study were not diagnostic of SRL as they can result from many other things. Teachers' answers about the cues that they used remained vague, and most of their ideas based on the evaluation of students' self-assessment as well as on the observation of off-task behavior or based on students' achievement outcomes. Comparable to the findings of Michalsky (2017), our teachers demonstrated limited knowledge about assessment instruments for SRL. Although many teachers referred to using portfolio or learning diaries in order to assess SRL, it remained unclear from teachers' answers which cues in portfolios and diaries teachers really use to identify SRL. A large share of teachers also reported to conduct reflective talks, or to base their SRL assessment on observations of students' behavior in the classroom, but again, teachers could not precisely point to the student activities that they would discuss or observe. Only very few teachers reported to have systematic observation schemes; rather, teachers referred to off-task behavior or inappropriate learning progress. This is worrying, as it has been shown that teachers' judgment accuracy improves when teachers draw their inferences from cues that are diagnostic of students' learning (Brunswik, 1956).

As to our last research question, we found some association between teachers' SRL conceptualization and their ideas about assessing SRL, but not for every variable. This inconsistent result is in line with the inconsistent evidence base regarding the association between teachers' knowledge and their judgment accuracy (e.g., Helmke et al., 2004; Rausch et al., 2015). As our results show, teachers who conceptualized SRL mainly as student autonomy and self-directedness reported more often to rely on cues that are not diagnostic of SRL than teachers who conceptualized SRL mainly as motivation or regulation.

\section{Limitations of the Study}

The findings of this study must be viewed considering methodological considerations. First, only the answers of 205 educators, who were voluntarily participating in this study, could be studied. Thus, these teachers might be more interested in the topic of SRL than the average teacher. Second, the data used in this study is self-reported, so social desirability in responses of teachers' SRL assessment may pose a problem, and it is not clear how far teachers' real assessment practice regarding SRL in their classroom is similar to their reported assessment practice. Third, the design of this study is cross-sectional, which means that the data only provides a snapshot of educators' conceptualization of SRL. It also means that it is not possible to establish whether a causal relationship exists between educators' conceptualization of SRL and their ideas about assessing SRL.

\section{Implications for Future Research, Educational Policy, and Practice}

We derived six implications for future research, policy, and practice from our findings. First, contextualizing our result is 
challenging, in particular, because of a lack of available data on teachers' assessment accuracy regarding SRL (see Michalsky, 2017). To date, research on teachers' SRL practice has been limited to their classroom behavior (e.g., Perry, 1998; Dignath and Büttner, 2018), their beliefs (e.g., Vosniadou et al., 2020), or their knowledge about metacognition (e.g., Zohar and Barzilai, 2013). This study looked at educators' conceptualization of SRL and its assessment. More research is needed to see if patterns of teachers' SRL concepts and the associated ideas about how to diagnose SRL in students are related to teachers' classroom behavior.

Second, since previous research has indicated that teachers' self-reported SRL practice is not necessarily what teachers are doing in the classroom (e.g., Dignath-van Ewijk et al., 2013), we may have to doubt that teachers are using the diagnostic cues and assessment instruments that they report to apply. Future research should investigate teachers' SRL assessment beyond teachers' selfreport, for example, by means of classroom observation or in experimental lab studies.

Third, in order to shed light on the mismatch of educators' focus on the forethought phase when describing SRL found in this study and the evidence from classroom observation studies indicating that teachers rather omit the forethought phase of the SRL cycle with regard to their SRL practice, more classroom observation research in combination with teacher inquiry is needed (see also Butler, 2002; Perry, 2002). Rather than solely analyzing classroom observations by means of systematic coding schemes that are derived from scientific conceptualizations of SRL as has been done in many studies (see Dignath and Veenman, 2020), researchers should watch the classroom videos together with the educators to ask them about their intended SRL practice and SRL assessment in order to be able to uncover inconsistencies between teachers' ideas about SRL and its assessment and their implementation in the classroom.

Fourth, whereas teachers acknowledge the importance of regulating one's motivation for learning, there is little evidence about how teachers think about the regulation of one's emotion. Since research has illustrated the impact of academic emotions for learning (e.g., Pekrun, 2006) and the importance of selfregulation of one's academic emotions (e.g., Ben-Eliyahu, 2019), more research is needed to uncover why educators do not associate SRL with the regulation of emotions yet.

Fifth, our approach to derive patterns for teachers' conceptualization of SRL has proven helpful in order to identify associations with their SRL assessment. However, other research has suggested that teachers can hold inconsistent beliefs about SRL (Vosniadou et al., 2020). Thus, disentangling the co-occurrence of such inconsistent beliefs could be helpful to find out how conceptual change of teachers can be elicited. In-depth studies with educators could help to shed light on this inconsistency within their conceptualization of SRL.

Sixth, when investigating teachers' notion of SRL, research has so far neglected teachers' own SRL. However, this plays a role both for teachers' SRL and for their self-regulation of teaching (Kramarski and Michalsky, 2009). Teachers' conceptualization of SRL may affect not only how they assess and promote SRL in the classroom but also their own self-regulation. Yet, teachers' own self-regulation will eventually affect their SRL practice (Butler and Schnellert, 2012), as research has suggested that educators need to be good self-regulated learners themselves in order to effectively teach self-regulation strategies to their students (Randi, 2004; Peeters et al., 2014; Kramarski and Kohen, 2017). More research is needed to examine the relationship between teachers' conceptualization of SRL and their own self-regulation, and, eventually with their SRL practice.

Finally, for teaching adaptively, educators need to understand their students' needs (Corno, 2008). To this end, they need to be able to identify how self-regulated each student is and which students still need more support. As instructional quality varies as a function of teachers' assessment accuracy (Van de Pol et al., 2010), it is argued that future intervention strategies for teachers to promote SRL should also address how teachers can identify SRL and which cues they can use to do so. As this has been found to be related to teachers' conceptualization of SRL, teacher intervention should first identify these conceptualizations and support teachers in developing comprehensive views on SRL processes.

\section{CONCLUSION}

We conducted an examination of educators' conceptualization of SRL, identified three patterns to classify these conceptualizations, and investigated how such conceptualization is associated with teachers' assessment of SRL. We found that, in particular, teachers who conceptualize SRL as student autonomy and selfdirectedness might be at risk for using cues that are not diagnostic of SRL when attempting to identify their students' self-regulation skills. This raises questions about the impact that teachers' conceptualization of SRL has on their assessment accuracy for SRL, which might, in turn, affect teachers' adaptive teaching and promoting SRL in the classroom.

Furthermore, research is needed to establish whether a teacher intervention approach targeting educators' conceptualization of SRL is effective to support them in identifying cues that are diagnostic of SRL among their students. As teachers have to adapt their learning environments to the self-regulatory level of their students (White and DiBenedetto, 2015), they first need to identify which self-regulatory strategies students are already able to apply and what they still need to develop (Boekaerts, 1999). Uncovering educators' conceptualization of SRL might on the one hand be fruitful to start teacher intervention and could eradiate on teachers' SRL assessment accuracy as well as their promotion of SRL in the classroom. Moreover, it might serve as indicator for teachers who could be at risk for misconception of SRL and, consequently, misleading cues when attempting to identify their students' SRL skills.

\section{DATA AVAILABILITY STATEMENT}

The raw data supporting the conclusions of this article will be made available by the authors, without undue reservation. 


\section{ETHICS STATEMENT}

Ethical review and approval was not required for the study on human participants in accordance with the local legislation and institutional requirements. The patients/participants provided their written informed consent to participate in this study.

\section{REFERENCES}

Alexander, J. M., Carr, M., and Schwanenflugel, P. J. (1995). Development of metacognition in gifted children: directions for future research. Dev. Rev. 15, 1-37. doi: 10.1006/drev.1995.1001

Askell-Williams, H., Lawson, M. J., and Skrzypiec, G. (2012). Scaffolding cognitive and metacognitive strategy instruction in regular class lessons. Instruct. Sci. 40, 413-443. doi: 10.1007/s11251-011-9182-5

Banfield, J., and Raftery, A. (1993). Model-based Gaussian and non-Gaussian clustering. Biometrics 49, 803-821. doi: 10.2307/2532201

Ben-Eliyahu, A. (2019). Academic emotional learning: a critical component of selfregulated learning in the emotional learning cycle. Educ. Psychol. 54, 84-105. doi: 10.1080/00461520.2019.1582345

Ben-Eliyahu, A., and Linnenbrink-Garcia, L. (2013). Extending self-regulated learning to include self-regulated emotion strategies. Motiv. Emot. 37, 558-573. doi: 10.1007/s11031-012-9332-3

Boekaerts, M. (1999). Self-regulated learning: where we are today. Intern. J. Educ. Res. 31, 445-457. doi: 10.1016/s0883-0355(99)00014-2

Boekaerts, M. (2002). "Toward a model that integrates motivation, affect and learning," in Development and Motivation: Joint Perspectives, eds L. Smith, C. Rogers, and P. Tomlinson (Leicester: British Psychological Society).

Boekaerts, M., and Cascallar, E. (2006). How far have we moved toward the integration of theory and practice in self-regulation? Educ. Psychol. Rev. 18, 199-210. doi: 10.1007/s10648-006-9013-4

Bolhuis, S., and Voeten, M. J. (2001). Toward self-directed learning in secondary schools: what do teachers do? Teach. Teach. Educ. 17, 837-855. doi: 10.1016/ s0742-051x(01)00034-8

Brühwiler, C., and Blatchford, P. (2011). Effects of class size and adaptive teaching competency on classroom processes and academic outcome. Learn. Instruct. 21, 95-108. doi: 10.1016/j.learninstruc.2009.11.004

Brunswik, E. (1956). Perception and the Representative Design of Psychological Experiments. Berkeley, CA: University of California Press.

Butler, D. L. (2002). Qualitative approaches to investigating self-regulated learning: contributions and challenges. Educ. Psychol. 37, 59-63. doi: 10.1207/ S15326985EP3701_7

Butler, D. L., and Schnellert, L. (2012). Collaborative inquiry in teacher professional development. Teach. Teach. Educ. 28, 1206-1220. doi: 10.1016/j.tate.2012.07. 009

Callan, G. L., and Shim, S. S. (2019). How teachers define and identify self-regulated learning. Teach. Educ. 54, 295-312. doi: 10.1080/08878730.2019.1609640

Corno, L. Y. N. (2008). On teaching adaptively. Educ. Psychol. 43, 161-173. doi: 10.1080/00461520802178466

De Corte, E., Verschaffel, L., and Masui, C. (2004). The CLIA-model: a framework for designing powerful learning environments for thinking and problem solving. Eur. J. Psychol. Educ. 19, 365-384. doi: 10.1007/bf03173216

Dicke, A. L., Lüdtke, O., Trautwein, U., Nagy, G., and Nagy, N. (2012). Judging students' achievement goal orientations: are teacher ratings accurate? Learn. Individ. Differ. 22, 844-849. doi: 10.1016/j.lindif.2012.04.004

Dignath, C., and Büttner, G. (2018). Teachers' direct and indirect promotion of self-regulated learning in primary and secondary school mathematics classesinsights from video-based classroom observations and teacher interviews. Metacogn. Learn. 13, 127-157. doi: 10.1007/s11409-018-9181-x

Dignath, C., Büttner, G., and Langfeldt, H. P. (2008). How can primary school students learn self-regulated learning strategies most effectively?: a metaanalysis on self-regulation training programmes. Educ. Res. Rev. 3, 101-129. doi: 10.1016/j.edurev.2008.02.003

Dignath, C., and Veenman, M. V. J. (2020). The role of direct strategy instruction and indirect activation of self-regulated learning - evidence from classroom observation studies. Educ. Psychol. Rev. doi: 10.1007/s10648-020-09534-9530

\section{AUTHOR CONTRIBUTIONS}

CD developed the research design and the coding schemes, and supervised the study. LS helped with the data collection and the coding of the open teacher answers. Both authors contributed to the article and approved the submitted version.

Dignath-van Ewijk, C., Dickhäuser, O., and Büttner, G. (2013). Assessing how teachers enhance self-regulated learning: a multiperspective approach. J. Cogn. Educ. Psychol. 12, 338-358. doi: 10.1891/1945-8959.12.3.338

Dignath-van Ewijk, C., and van der Werf, G. (2012). What teachers think about self-regulated learning: investigating teacher beliefs and teacher behavior of enhancing students' self-regulation. Educ. Res. Intern. 2012:713. doi: 10.1155/ 2012/741713

Efklides, A. (2011). Interactions of metacognition with motivation and affect in self-regulated learning: the MASRL model. Educ. Psychol. 46, 6-25. doi: 10. 1080/00461520.2011.538645

Flavell, J. H. (1979). Metacognition and cognitive monitoring: a new area of cognitive-developmental inquiry. Am. Psychol. 34:906. doi: 10.1037/0003-066x. 34.10 .906

Glogger-Frey, I., Ampatziadis, Y., Ohst, A., and Renkl, A. (2018). Future teachers' knowledge about learning strategies: misconcepts and knowledge-in-pieces. Think. Skills Creat. 28, 41-55. doi: 10.1016/j.tsc.2018.02.001

Hattie, J., and Yates, G. C. (2013). Visible Learning and the Science of How We Learn. New York, NY: Routledge. doi: 10.4324/9781315885025

Helmke, A., Hosenfeld, I., and Schrader, F. W. (2004). "Vergleichsarbeiten als instrument zur verbesserung der diagnosekompetenz von lehrkräften," in Schulleitung und Schulentwicklung, eds R. Arnold and C. Griese (Hohengehren: Schneider-Verlag), 119-144.

IBM Corp (2016). IBM SPSS Statistics for Windows, Version 24.0. Armonk, NY: IBM Corp.

Karing, C. (2009). Diagnostische kompetenz von grundschul- und gymnasiallehrkräften im leistungsbereich und im bereich interessen. Zeitschr. Pädag. Psychol. 23, 197-209. doi: 10.1024/1010-0652.23.34.197

Kiewra, K. A. (2002). How classroom teachers can help students learn and teach them how to learn. Theory Pract. 41, 71-80. doi: 10.1207/s15430421tip4102 3

Kistner, S., Rakoczy, K., Otto, B., Dignath-van Ewijk, C., Büttner, G., and Klieme, E. (2010). Promotion of self-regulated learning in classrooms: investigating frequency, quality, and consequences for student performance. Metacogn. Learn. 5, 157-171. doi: 10.1007/s11409-010-9055-3

Kramarski, B., and Michalsky, T. (2009). Investigating preservice teachers' professional growth in self-regulated learning environments. J. Educ. Psychol. 101:161. doi: 10.1037/a0013101

Kramarski, B., and Kohen, Z. (2017). Promoting preservice teachers' dual selfregulation roles as learners and as teachers: Effects of generic vs. specific prompts. Metacogn. Learn. 12, 157-191.

Lawson, M. J., Vosniadou, S., Van Deur, P., Wyra, M., and Jeffries, D. (2019). Teachers' and students' belief systems about the self-regulation of learning. Educ. Psychol. Rev. 31, 223-251. doi: 10.1007/s10648-0189453-7

Leutwyler, B., and Maag Merki, K. (2009). School effects on students's self-regulated learning. A multivariate analysis of the relationship between individual perceptions of school processes and cognitive metacognitive and motivational dimensions of self-regulated learning. J. Educ. Res. 1, 197-223.

Mayring, P., and Gläser-Zikuda, M. (2008). Die Praxis der Qualitativen Inhaltsanalyse. Weinheim: Beltz.

Michalsky, T. (2017). What teachers know and do about assessing students' self-regulated learning. Teach. Coll. Rec. 119, 1-16.

Organisation for Economic Co-operation and Development [OECD] (2014). Education at a Glance 2014: OECD Indicators. Paris: OECD.

Panadero, E. (2017). A review of self-regulated learning: six models and four directions for research. Front. Psychol. 8:422. doi: 10.3389/fpsyg.2017. 00422

Paris, S. G., and Paris, A. H. (2001). Classroom applications of research on self-regulated learning. Educ. Psychol. 36, 89-101. doi: 10.1207/s15326985ep 3602_4 
Peeters, J., De Backer, F., Reina, V. R., Kindekens, A., Buffel, T., and Lombaerts, K. (2014). The role of teachers' self-regulatory capacities in the implementation of self-regulated learning practices. Proc. Soc. Behav. Sci. 116, 1963-1970. doi: 10.1016/j.sbspro.2014.01.504

Pekrun, R. (2006). The control-value theory of achievement emotions: assumptions, corollaries, and implications for educational research and practice. Educ. Psychol. Rev. 18, 315-341. doi: 10.1007/s10648-0069029-9

Pekrun, R., Goetz, T., Titz, W., and Perry, R. P. (2002). Academic emotions in students' self-regulated learning and achievement: a program of qualitative and quantitative research. Educ. Psychol. 37, 91-105. doi: 10.1207/S153269 85EP3702_4

Perry, N. E. (1998). Young children's self-regulated learning and contexts that support it. J. Educ. Psychol. 90:715. doi: 10.1037/0022-0663.90.4.715

Perry, N. E. (2002). Introduction: using qualitative methods to enrich understandings of self-regulated learning. Educ. Psychol. 37, 1-3. doi: 10.1207/ S15326985EP3701_1

Perry, N. E. (2013). Classroom processes that support self-regulation in young children. Br. J. Educ. Psychol. 10, 45-68.

Pintrich, P. R. (1999). The role of motivation in promoting and sustaining self-regulated learning. Intern. J. Educ. Res. 31, 459-470. doi: 10.1016/s08830355(99)00015-4

Pintrich, P. R. (2000). "The role of goal orientation in self-regulated learning," in Handbook of Self-Regulation, eds M. Boekaerts, M. Zeidner and P. R. Pintrich (Cambridge, MA: Academic Press), 451-502. doi: 10.1016/B978-012109890-2/ 50043-3

Pintrich, P. R. (2004). A conceptual framework for assessing motivation and selfregulated learning in college students. Educ. Psychol. Rev. 16, 385-407. doi: 10.1007/s10648-004-0006-x

Questback GmbH (2017). EFS Survey, Version Summer 2017. Köln: Questback $\mathrm{GmbH}$.

Randi, J. (2004). Teachers as self-regulated learners. Teach. Coll. Rec. 106, 18251853. doi: $10.1111 / \mathrm{j} .1467-9620.2004 .00407 . \mathrm{x}$

Rausch, T., Matthäi, J., and Artelt, C. (2015). Mit wissen zu akkurateren urteilen? Zeitschr. Entwicklungspsychol. Pädag. Psychol. 47, 147-158. doi: 10.1026/0049$8637 / \mathrm{a} 000124$

Seidel, T., and Shavelson, R. J. (2007). Teaching effectiveness research in the past decade: the role of theory and research design in disentangling metaanalysis results. Rev. Educ. Res. 77, 454-499. doi: 10.3102/003465430731 0317

Shavelson, R. J., and Stern, P. (1981). Research on teachers' pedagogical thoughts, judgments, decisions, and behavior. Rev. Educ. Res. 51, 455-498. doi: 10.3102/ 00346543051004455

Shepard, L., Hammerness, K., Darling-Hammond, L., Rust, F., Baratz, S. J., Gordon, E., et al. (2005). "Assessment," in Preparing Teachers for a Changing World: What Teachers Should Learn and be Able to do, eds L. DarlingHammond and J. Bransford (San Francisco, CA: John Wiley \& Sons, Inc), 275-326.

Shulman, L. (1987). Knowledge and teaching: foundations of the new reform. Harv. Educ. Rev. 57, 1-23.

Spruce, R., and Bol, L. (2015). Teacher beliefs, knowledge, and practice of selfregulated learning. Metacogn. Learn. 10, 245-277. doi: 10.1007/s11409-0149124-0

Südkamp, A., Kaiser, J., and Möller, J. (2012). Accuracy of teachers' judgments of students' academic achievement: a meta-analysis. J. Educ. Psychol. 104:743. doi: $10.1037 / \mathrm{a} 0027627$

Thiede, K. W., Brendefur, J. L., Osguthorpe, R. D., Carney, M. B., Bremner, A., Strother, S., et al. (2015). Can teachers accurately predict student performance? Teach. Teacher Educ. 49, 36-44.

Van de Pol, J., De Bruin, A. B., van Loon, M. H., and Van Gog, T. (2019). Students' and teachers' monitoring and regulation of students' text comprehension: effects of comprehension cue availability. Contemp. Educ. Psychol. 56, 236-249. doi: 10.1016/j.cedpsych.2019. 02.001
Van de Pol, J., Volman, M., and Beishuizen, J. (2010). Scaffolding in teacherstudent interaction: a decade of research. Educ. Psychol. Rev. 22, 271-296. doi: 10.1007/s10648-010-9127-6

Veenman, M. V., and van Cleef, D. (2019). Measuring metacognitive skills for mathematics: students' self-reports versus on-line assessment methods. ZDM 51, 691-701. doi: 10.1007/s11858-018-1006-5

Veenman, M. V., Van Hout-Wolters, B. H., and Afflerbach, P. (2006). Metacognition and learning: conceptual and methodological considerations. Metacogn. Learn. 1, 3-14. doi: 10.1007/s11409-006-6893-0

Vosniadou, S., Lawson, M. J., Wyra, M., Van Deur, P., Jeffries, D., and Ngurah, D. I. G. (2020). Pre-service teachers' beliefs about learning and teaching and about the self-regulation of learning: a conceptual change perspective. Intern. J. Educ. Res. 99:101495. doi: 10.1016/j.ijer.2019.101495

Weinstein, C. E., and Mayer, R. E. (1986). “The teaching of learning strategies," in Handbook of Research on Teaching, ed. M. Wittrock (New York, NY: Macillan), 315-327.

White, M. C., and DiBenedetto, M. K. (2015). Self-Regulation and the Common Core: Application to ELA Standards. Abingdon: Routledge. doi: 10.4324/ 9781315882840

Whitebread, D., and Neale, D. (2020). Metacognition in early child development. Transl. Issues Psychol. Sci. 6, 8-14. doi: 10.1037/tps0000223

Winne, P. H., and Perry, N. E. (2000). "Measuring self-regulated learning," in Handbook of Self-Regulation, eds P. R. Pintrich and M. Zeidner (Cambridge, MA: Academic Press), 531-566. doi: 10.1016/b978-012109890-2/ 50045-7

Zepeda, C. D., Hlutkowsky, C. O., Partika, A. C., and Nokes-Malach, T. J. (2019). Identifying teachers' supports of metacognition through classroom talk and its relation to growth in conceptual learning. J. Educ. Psychol. 111:522. doi: 10.1037/edu0000300

Zimmerman, B. J. (2000). “Attaining self-regulation: a social cognitive perspective," in Handbook of Self-Regulation, eds M. Boekaerts, P. R. Pintrich, and M. Zeidner (Cambridge, MA: Academic Press), 13-39. doi: 10.1016/b978-012109890-2/ 50031-7

Zimmerman, B. J. (2002). Becoming a self-regulated learner: an overview. Theory Pract. 41, 64-70.

Zimmerman, B. J., and Schunk, D. H. (2011). "Motivational sources and outcomes of self-regulated learning and performance," in Handbook of Self-Regulation of Learning and Performance, eds B. J. Zimmerman and D. H. Schunk (New York, NY: Routledge), 49-64.

Zohar, A., and Barzilai, S. (2013). A review of research on metacognition in science education: current and future directions. Stud. Sci. Educ. 49, 121-169. doi: 10.1080/03057267.2013.847261

Zohar, A., and David, A. B. (2008). Explicit teaching of meta-strategic knowledge in authentic classroom situations. Metacogn. Learn. 3, 59-82. doi: 10.1007/s11409007-9019-4

Zohar, A., and Lustov, E. (2018). "Challenges in addressing metacognition in professional development programs in the context of instruction of higherorder thinking," in Contemporary Pedagogies in Teacher Education and Development, eds Y. Weinberger and Z. Libman (Norderstedt: Books on Demand). doi: 10.5772/intechopen.76592

Zohar, A., and Schwartzer, N. (2005). Assessing teachers' pedagogical knowledge in the context of teaching higher-order thinking. Intern. J. Sci. Educ. 27, 1595-1620. doi: 10.1080/09500690500186592

Conflict of Interest: The authors declare that the research was conducted in the absence of any commercial or financial relationships that could be construed as a potential conflict of interest.

Copyright (c) 2020 Dignath and Sprenger. This is an open-access article distributed under the terms of the Creative Commons Attribution License (CC BY). The use, distribution or reproduction in other forums is permitted, provided the original author(s) and the copyright owner(s) are credited and that the original publication in this journal is cited, in accordance with accepted academic practice. No use, distribution or reproduction is permitted which does not comply with these terms. 